\title{
ESCREVENDO POR SOBRE A TERRA: AS FAZENDAS-MODELO EM MINAS GERAIS (1906-1915)
}

DOI: http://dx.doi.org/10.1590/2236-3459/25589

\author{
Irlen Antônio Gonçalves \\ Centro Federal de Educação Tecnológica de Minas Gerais, Brasil.
}

Daniela Pereira Versieux

Instituto Federal de Educação, Ciência e Tecnologia de Goiás, Brasil.

\section{$\cos 80$}

\begin{abstract}
Resumo
As fazendas-modelo, instituições de ensino agrícola de caráter prático, foram implantadas pelo Brasil e, em Minas Gerais, na capital e em algumas cidades do interior. Elas foram instituídas como parte de uma política pública nacional nos anos iniciais do século 20. Em Minas Gerais foram criadas entre os anos de 1906 e 1915. Neste texto nos propomos compreender como as fazendas-modelo surgiram como instituições de ensino, sua materialidade e os sujeitos da aprendizagem e conhecimentos. Assim, será realizado um diálogo e uma problematização das fontes históricas de diversas origens, tais como a legislação, os anais do Congresso Legislativo, os relatórios anuais e expedientes da diretoria de Agricultura e os relatórios anuais da Secretaria da Agricultura.

Palavras-chave: fazendas-modelo, ensino agrícola, campos de demonstração.
\end{abstract}

\section{WRITING UPON THE LAND: MODEL FARMS IN MINAS GERAIS (1906-1915)}

\begin{abstract}
Model farms, institutions for practical agricultural education, were spread all over Brazil and, in Minas Gerais, in the capital and other country towns. They were instituted as part as a national public policy in the first years of the $20^{\text {th }}$ century. In Minas Gerais, were created between the years 1906 and 1915. In this text we propose to understand how the model farms came to be education institutions, in the aspects of her materiality and the subject of learning and knowledge. Then, there will be a dialogue and a questioning of the historical sources of many roots, such as legislation, the proceedings of the Congress Legislature, annual reports and records of the Board of Agriculture and the annual reports of the Secretary of Agriculture.

Key-words: model farms, agricultural education, demonstration fields.
\end{abstract}




\section{ESCREVENDO POR SOBRE A TERRA: \\ LAS HACIENDAS MODELO EN MINAS GERAIS (1906-1915)}

\section{Resumen}

Las haciendas modelo, instituciones de enseñanza agrícola práctica, se han implantado en todo el Brasil y en Minas Gerais, en la capital, y en algunos pueblos. Fueron instituidas como parte de una política pública nacional en los primeros años del siglo 20. En Minas Gerais fueron creadas entre los años 1906 y 1915. En este trabajo nos proponemos entender cómo las haciendas modelo surgieron como instituciones educativas, en los aspectos de su materialidad y de los sujetos de aprendizaje y conocimiento. Por lo tanto, habrá un diálogo y un cuestionamiento de las fuentes históricas de diversos orígenes, tales como: la legislación, los procedimientos del Congreso Legislativo, los informes anuales y los registros de la Junta de Agricultura y los informes anuales de la Secretaría de Agricultura.

Palabras-clave: haciendas modelo, la enseñanza agrícola, campos de demostración.

\section{ÉCRIVANT A PROPOS DE LA TERRE: LES FERMES MODELES DANS L'ÉTAT DE MINAS GERAIS (1906-1915)}

\section{Résumé}

Les fermes modèles, des établissements d'enseignement pratique de l'agriculture, ont été mises en place au Brésil et à Minas Gerais, dans la capitale et dans certaines villes rurales. Ces fermes ont éte instituées dans le cadre d'un programme national de politiques publiques au début du 20e siècle. À l'État de Minas Gerais elles ont éte créées entre les années 1906 et 1915. Dans ce texte nous nous proposons de comprendre comment les fermes modèles sont apparues, comme des établissements d'enseignement, en tenant compte de sa matérialité et en considérant les sujets de l'apprentissage et de la connaissance. Ainsi, un dialogue aura lieu et aussi une remise en cause des sources historiques d'origines diverses telles que : la législation, les annales du Congrès Législatif, les rappots annuels, les registres de la direction de l'Agriculture et les rapports annuels du Sécretariat de l'Agriculture

Mots-clé: fermes-modèles, l'enseignement agricole, des champs de démonstration. 
$\mathbf{N}$ O ano de 1906 registram-se ações governamentais para a implantação de política nacional para os assuntos relacionados à agricultura e para a formação do trabalhador do campo. Foi com o decreto n. 1.606, de 29 de dezembro de 1906, que o presidente do Brasil, Affonso Augusto Moreira Penna ${ }^{1}$, criou o Ministério dos Negócios da Agricultura, Indústria e Comércio.

O referido decreto, no artigo $2^{\circ}$, explicita as ações que seriam desenvolvidas no Ministério, relativas à agricultura e à indústria animal. Dentre algumas ações, para o que interessa a discussão proposta, destaca-se a formação profissional.

Sobre a criação do Ministério, escreve o presidente Affonso Pena na mensagem enviada ao Congresso Nacional, em 1907:

A Lei n. 1.606, de 29 de dezembro de 1906, creando o Ministério da Agricultura, é um acto de grande sabedoria do Congresso e foi recebida com aplauso pela nossa importante classe agrícola. [...] Para corresponder às esperanças que despertou sua creação, não deve o novo ministério ser simples aparelho burocrático, composto de secções e divisões administrativas, e sim um conjunto de órgãos que tenham a seu cargo serviços especiais propulsores da indústria agrícola, nas suas variadas faces, como sejam: ensino teórico e prático, campos de demonstração, postos zootechnicos e meteorológicos, serviços de imigração, colonização e de propaganda, estatística agrícola, estudos geológicos e outros semelhantes. (Penna, 1907, p. 48)

Não foi sem razão que em 20 de outubro de 1910, já no mandato de Nilo Peçanha, com o decreto n. 8.319, foi criado o Ensino Agronômico e aprovado o seu respectivo regulamento. No artigo $2^{\circ}$ o ensino agrícola ficou assim estruturado: ensino superior; ensino médio ou teórico-prático; ensino prático; aprendizados agrícolas; ensino primário agrícola; escolas especiais de agricultura; escolas domésticas agrícolas; cursos ambulantes; cursos conexos com o ensino agrícola; consultas agrícolas; conferências agrícolas.

A partir do citado decreto algumas instituições foram criadas com vistas à formação do trabalhador nacional: decreto n. 8.255, de 9 de novembro de 1910 , criou no município de Campos, Estado do Rio de Janeiro, uma estação experimental para cana de açúcar; decreto n. 8.357, de 9 de novembro de 1910, criou na sede do município de São Simão, Estado de São Paulo, um aprendizado agrícola; decreto n. 8.358, de 9 de novembro de 1910, criou um aprendizado agrícola na cidade de Barbacena, Estado de Minas Gerais; decreto n. 8.305, de 10 de novembro de 1910, criou no município do São Luiz de Missões, Estado do Rio Grande do Sul, um aprendizado agrícola. Como se vê, as inciativas de instituir políticas para a formação do trabalhador campesino foram implantadas no âmbito nacional.

\footnotetext{
${ }^{1}$ Ressaltamos que o presidente Affonso Penna era mineiro da cidade de Santa Bárbara e foi presidente do Estado de Minas Gerais no período de 1892 a 1894 e vice-presidente na gestão de Francisco Salles (1902-1906), além de ter sido deputado em várias legislaturas e ministro de governo. Deixou o governo mineiro para a candidatura a presidência da República, formando a chapa única com Nilo Peçanha. Com sua morte, em 24 de julho de 1909, Nilo Peçanha assumiu a presidência. 
De fato havia, na política pública brasileira, uma preocupação com a modernização da produção agrícola pela via da institucionalização do saber do ofício no trato das questões do campo. Por isso não é sem razão que nos Estados brasileiros também foram produzidas políticas para formar o trabalhador nacional do campo.

Em Minas Gerais, não diferente de outros Estados, a partir do ano de 1906, o governo, sob a presidência João pinheiro ${ }^{2}$, criou-se as fazendas-modelo que, segundo Maria Auxiliadora Faria, foram instituídas

com o objetivo de absorverem alunos que mais se destacassem nos cursos elementares. Eram, portanto, segundo a Lei $n^{\circ} 444$, de 1906, instituições de ensino médio agrícola. O Regulamento de 1911 alterou esse objetivo. [...] As fazendas [modelo] deveriam, de acordo com os artigos 61 e 62 do referido Regulamento, receber, por período de 30 dias, trabalhadores indicados por fazendeiros e pelo Estado para estágio e aquisição de "destreza no manejo de máquinas agrícolas". Deviam receber também moços nunca menores de 18 anos, "de conduta morigerada", como aprendizes de técnicas agrícolas e veterinárias, por período mínimo de 10 meses. (Faria, 1992, p. 273)

De fato, o presidente de Minas Gerais, João Pinheiro da Silva, implantou no Estado as fazendas-modelo, introduzindo-as como uma iniciativa estatal e gratuita. Contudo, o objetivo inicial de João Pinheiro, de torná-las estabelecimentos de ensino secundário que absorvessem os alunos que mais se destacassem nos cursos primários, não se consolidou. Já em 1907 elas dedicavam-se, tanto à formação de mestres de cultura - um tipo de ensino secundário profissional agrícola apenas prático -, quanto à formação de operários agrícolas, sem nenhum compromisso com o ensino teórico. $\mathrm{Na}$ verdade, o regulamento de 1911, citado por Faria, referendou a política traçada por João Pinheiro, ampliando-a. Ou, como quer Otávio Dulci (2005), institucionalizou essa política.

Quanto ao seu caráter secundário, foi de fato definido nas leis n. 438 e 444, de 1906, como previsto inicialmente. Para compreender a opção de João Pinheiro pelas fazendas modelo, pelo seu caráter estritamente prático e de difícil enquadramento em algum nível de ensino, tal como hoje se compreende o sentido dessa expressão, optamos por fazer uma inserção entre as fazendas-modelo e os campos de demonstração instituídos por Crispim Jacques Bias Fortes, pelo decreto n. 960, de 1896.

Podemos afirmar que João Pinheiro apoiou-se no regulamento dos campos de demonstração e de outras instituições de ensino agrícola de fins de século 19 para elaborar a sua política das fazendas-modelo. Mesmo retirado em Caeté, cuidando de sua fábrica de cerâmica, João Pinheiro manteve contato com as discussões que permearam a criação, implantação e desmonte desses estabelecimentos.

\footnotetext{
${ }^{2}$ Político, industrial e bacharel, João Pinheiro nasceu na cidade do Serro, no centro-norte de Minas Gerais. Foi um dos fundadores do partido republicano em Minas Gerais, ocupando cargos de relevo no primeiro governo da república, além de assumir interinamente o cargo de presidente do Estado, em 1891. Foi eleito deputado no Congresso Constituinte do Estado, renunciou ao mandato em 1891 e retirou-se em Caeté, onde fundou uma fábrica de cerâmicas, dedicando-se também à docência na Faculdade Livre de Direito (Monteiro, 1994). Voltou à vida pública em 1899, eleito vereador do município, onde passou a exercer a função de agente executivo e presidente da Câmara Municipal. Em 1903 presidiu a Comissão Fundamental do Congresso Agrícola, Industrial e Comercial. Logo em seguida foi eleito senador da República (1905) e presidente de Minas Gerais (1906-1908). 
Podemos dizer que os campos de demonstração foram precursores das fazendasmodelo, às quais João Pinheiro tentou imprimir um caráter acentuadamente prático, suprimindo a parte teórica do currículo e as explicações e preleções previstos para estes estabelecimentos, além de racionalizar a sua administração. De qualquer forma, as semelhanças entre os campos de demonstração, do final do século 19, e as fazendasmodelo do inicio do século 20, separadas por apenas uma década, são evidentes, assim como o são também as dessemelhanças.

Carlos Prates (Minas Gerais, 1911) informou ter sido de pouco mais de um ano a duração dos campos de demonstração, ao passo que as fazendas-modelo seguiram por quase uma década (1906-1914), enquanto política de ensino agrícola prático. Evidenciase, assim, uma crescente institucionalização desse tipo de estabelecimento agrícola.

No que diz respeito aos aprendizes, várias considerações são possíveis. Nos campos de demonstração estes deveriam ter entre 14 e 20 anos, serem órfãos e pobres, recomendáveis pelo seu comportamento e amor ao trabalho. Deveriam ainda saber ler e escrever, além de dominar as quatro operações aritméticas (dec. n. 960/1896, art. 31). O número de aprendizes seria entre seis e doze, anualmente, e deveriam permanecer por dois anos no estabelecimento. Os aprendizes receberiam complementação da sua instrução primária elementar e

o ensino prático dos métodos racionais de cultura, uso de instrumentos e máquinas agrícolas, cuidados a dispensar aos animais, de modo a se tornarem operários modelos, administradores aptos para a direção prática das fazendas e chefes de culturas e a serem capazes de vulgarizar os métodos, cujo conhecimento e aplicação têm os campos práticos em vista. (Dec. n. 960/1896, art. 32).

Assim, os aprendizes dos campos de demonstração deveriam se tornar operários modelos e serem jovens o suficiente para desenvolver o amor ao trabalho, numa referência à chamada vagabundagem que imperava na massa da população. Sendo órfãos, provavelmente, não teriam passado pela escola do trabalho, não teriam aprendido com seus pais a lida do campo, pois sendo que "os poucos conhecimentos necessários para a prática da agricultura extensiva se adquirem pelas lições práticas dos pais [...], os órfãos de lavradores [...] carecem de instrução e de uma educação para o trabalho"3. Não teriam aprendido, pois, a rotina, os métodos agrícolas que se queria superar. Além disso seriam, ao mesmo tempo, formados para operários e administradores de fazenda. Os únicos aprendizes dos campos de demonstração dos quais tive notícia não se enquadraram neste perfil (Versieux, 2010).

Nas fazendas-modelo os alunos deveriam ser trabalhadores agrícolas e nunca menores de 18 anos. Preconizou-se uma instrução técnica voltada para um público adulto e trabalhador. As fazendas receberiam números variáveis de aprendizes, de acordo com o tipo em que se enquadravam, sendo de dez a trinta pessoas. Foram previstas duas modalidades de instrução. Uma mais aligeirada, que durava no máximo 30 dias e que formava trabalhadores agrícolas enviados pelos fazendeiros do Estado. A este público ensinar-se-ia o manejo de máquinas agrícolas, também ministradas nas fazendas

${ }^{3}$ Revista Industrial de Minas Gerais, 15/06/1894, p. 230, col. 2. 
subvencionadas, às quais fazemos referência mais adiante. O outro tipo de instrução, também prática, poderia durar até 10 meses, formando mestres de cultura. Estes deveriam ser agricultores práticos e

moços de conduta reconhecidamente morigerada, [...] aos quais serão dadas residência e alimentação gratuitas e transporte ferroviário somente no caso de reconhecida pobreza. Estes moços tomarão parte nos trabalhos diários da fazenda, durante o tempo necessário para que possam assistir e executar todas as operações relativas às culturas em exploração na fazenda, desde o amanho dos terrenos até as colheitas e o preparo de seus produtos, sendo instruídos ao mesmo tempo, em todos os detalhes das culturas e da administração. (Decreto n. 2.027/1907, art. 61, § único)

Esta última formação, de mestres de cultura, mais ampla e aprofundada, era compatível com aquela prevista para os campos de demonstração. Porém, em se tratando da legislação, foi muito mais restrita em termos de sujeitos da aprendizagem, visto que foi dispensada somente a alguns agricultores ${ }^{4}$. Em ambos os tipos de aprendizagem não se previu nenhum tipo de instrução teórica - primária ou secundária, propedêutica ou profissional. Não houve um currículo prescrito, com programas a serem cumpridos. Existiu a proposta de se ministrar conhecimentos básicos de agricultura e pecuária, tanto aos mestres de cultura, quanto aos aprendizes. O conteúdo foi dado pelo próprio trabalho agrícola que se pretendeu transformar e pelos chamados novos métodos que se intencionou disseminar pelo Estado. Tentamos captar este currículo utilizando-se de vários documentos, tais como alguns textos escritos por João Pinheiro, discussões de projetos de lei ocorridas no Congresso Legislativo mineiro, relatórios da diretoria de Agricultura e artigos publicados no jornal Minas Gerais.

O currículo das fazendas-modelo tinha por base o que se ensinava, em especial, nos anos iniciais de funcionamento da fazenda da Gameleira. Como recurso de comparação elaboramos também o currículo dos campos de demonstração instituídos em 1895, tendo por base unicamente o programa publicado com o decreto n. 960/1896, que regulamentou o funcionamento de tais campos. Apresentamos esses dois currículos nos quadros 1 e 2 para evidenciar a passagem de um currículo teórico-prático para um currículo essencialmente prático, implantado nas fazendas-modelo. Como em ambos os casos não houve distribuição de disciplinas por cadeiras e destas em séries, optamos por outra organização.

No quadro 1, no qual apresentamos o programa dos campos de demonstração, encontra-se separada a parte teórica da parte prática, sem aprofundar nos conteúdos trabalhados, restringindo-nos aos temas que apareceram no texto do decreto n. 960/1896. Estamos tratando, então, do currículo prescrito pela legislação. Já no quadro 2, referente ao currículo das fazendas-modelo, optamos por organizá-lo por temas e conteúdos específicos a serem desenvolvidos em cada um dos temas, pois o conteúdo foi todo prático, e em nenhum dos documentos consultados fez-se, implícita ou explicitamente, menção a uma parte teórica. Ao contrário, todos os documentos consultados referiram-se ao ensino essencialmente prático. A construção deste currículo não se baseou em um texto legislativo, como fizemos para os campos de demonstração. As referências que

\footnotetext{
${ }^{4}$ Sobre os mestres de cultura, ver Versieux (2010).
} 
buscamos para elaborá-lo resultaram também em um currículo prescrito, que, contudo, sabemos que foi implantado, ao menos parcialmente. Não podemos, no entanto, fazer essa mesma assertiva em relação ao currículo dos campos de demonstração.

Quadro 1 -

Currículo dos campos de demonstração do Estado de Minas Gerais, 1896.

\begin{tabular}{|l|l|}
\hline \multicolumn{1}{|c|}{ Parte teórica } & \multicolumn{1}{c|}{ Parte prática } \\
\hline Física & Utilização de ferramentas e máquinas agrícolas \\
Química & Práticas das culturas, por métodos racionais \\
Ciências naturais & Cuidado com os rebanhos \\
Português & Horticultura e fruticultura: operações de cultura, enxertia e \\
Corografia do Brasil & poda \\
Aritmética & Ferraria - modo de usar as ferramentas, modo de ferrar \\
Geometria para as medidas & animais \\
superficiais e de volumes & Oficina de reparações - concertos mais frequentes exigidos \\
Agricultura & num serviço agrícola (de instrumentos aratórios, veículos) \\
Criação de animais & e boa conservação do material \\
\hline
\end{tabular}

Fonte: decreto n. 960/1896.

O quadro 1 revela que houve uma extensa parte teórica prevista no programa dos campos de demonstração, se comparado ao das fazendas-modelo. Diversas disciplinas, que em geral constavam dos currículos teórico-práticos, tanto médio, quanto superior, lá estavam. Dessa parte teórica tem-se um núcleo básico: Português, Aritmética, Corografia do Brasil - Geografia Física -, comum ao programa das escolas primárias de um modo geral, como observado em Gonçalves (2006).

Outra parte, que poderia ser situada num grau médio, foi constituída de conhecimentos científicos básicos: Física, Química, Ciências Naturais. Esta última disciplina em geral envolvia a Botânica, a Zoologia e a Geologia. Finalmente uma parte específica, que dava ao currículo um caráter técnico-agrícola: geometria para as medidas superficiais e de volumes, agricultura e criação de animais. Quanto à parte prática, esta foi bem próxima do currículo das fazendas-modelo: o aprendizado do manejo de instrumentos e máquinas agrícolas; a prática de culturas racionais e de cuidado com os rebanhos; horticultura e fruticultura; ferraria; e um pouco de mecânica agrícola, implícita na disciplina Oficina de Reparações.

O currículo que foi possível construir para as fazendas-modelo do início do século 20 é bem mais rico em informações. O seu cerne era tornar conhecidos os métodos da lavoura racional e metódica, em todas as suas fases, principalmente com a utilização de máquinas agrícolas, que diminuiriam a necessidade de mão-de-obra; de máquinas de beneficiamento, que agregariam valor aos produtos, melhorando a colocação dos mesmos nos mercados, aumentando os lucros dos produtores e, consequentemente, a riqueza pública; de adubação orgânica e inorgânica, que tornaria novamente disponível à agricultura os solos esgotados; a irrigação, que possibilitaria a utilização durante todo o ano de terras em locais sujeitos à seca periódica, minimizando os efeitos desta, prevenindo o produtor das variações e intempéries climáticas.

Podemos dizer que o currículo das fazendas-modelo incluía, de forma ampla, o domínio de algumas técnicas e métodos agrícolas - manejo de máquinas, irrigação, adubação - e também de alguns conhecimentos de administração de explorações 
agrícolas, principalmente a escrituração da produção. Mais especificamente, os aprendizes e também os fazendeiros que visitavam as fazendas-modelo poderiam ver

como se destoca ${ }^{5}$, como se revolve a terra com o moderno arado [...] de disco reversível, como se destorroa ${ }^{6}$ e como se grada; ver a tirada e condução da água que domina o terreno a plantar, como se faz a irrigação por inundação e como se faz a água atravessar em terreno frouxo as depressões da superfície. Verá mais a plantadeira mecânica e a regularidade e beleza do serviço por ela executado. A lição mais proveitosa é saber por quanto tudo isto fica e verificar que fica por muito pouco dinheiro. (Minas Gerais, 1907, p. 1)

A proposta era habituar os aprendizes a "orçar o custo de produção e a deduzir dele o lucro líquido, tudo por processos simples e práticos” (Minas Gerais, 1907, p. 1). João Pinheiro pretendia, de acordo com o que foi possível apurar, estimular aos aprendizes e fazendeiros como "se [ganhava] dinheiro, um dos fins para que foram criadas [as fazendas-modelo] no interesse geral e instante do povo" (Minas Gerais, 1907, p. 1).

A parte de contabilidade agrícola foi ministrada, exclusivamente, aos mestres de cultura que se formaram na fazenda-modelo da Gameleira. Implicou o aprendizado da escrituração das fazendas, entendidas como explorações ou empresas agrícolas. Assim, era fundamental ao mestre de cultura conseguir calcular gastos e deduzir lucros das plantações, planejando-as a partir de uma lógica racionalista e produtivista, bem como fazer todos esses cálculos por medida de área, para facilitar a percepção dos visitantes das fazendas-modelo sobre as vantagens dos métodos modernos sobre os rotineiros.

$\mathrm{Na}$ parte de criação de animais, sobressai-se a tentativa de introduzir reprodutores de raça para o melhoramento dos rebanhos mineiros. Isso compreendia a adaptação dos animais estrangeiros aos climas de Minas Gerais, processo denominado aclimatação ou aclimação, que consistia em manter o animal por um período de tempo em uma fazenda, até ele se acostumar ao novo ambiente e voltar a engordar, reproduzir, etc.; a produção de resistência a doenças, por meio da imunização com vacinas; e o que estamos considerando como inseminação natural assistida, que os contemporâneos denominavam lançamentos, ou seja, a reprodução propriamente dita, ou entre animais puros, ou a partir de cruzamentos com as raças consideradas indígenas.

Toda essa discussão, além do propósito de evidenciar a passagem de um currículo prático-teórico para um currículo essencialmente prático, objetivou elucidar alguns dos processos agrícolas e pecuários dos quais tratamos neste artigo.

Quadro 2 -

Currículo das fazendas-modelo de Minas Gerais, 1907.

\begin{tabular}{|c|l|l|}
\hline Tema & \multicolumn{2}{|c|}{ Conteúdo específico } \\
\hline Lavoura racional e metódica & Roçada & Semeadura \\
& Destocamento & Capina \\
& Aradura & Chegar Terra \\
& Destorroamento & Colheita \\
& Gradeamento & Preparo dos produtos \\
\hline
\end{tabular}

\footnotetext{
${ }^{5}$ Refere-se ao ato de destocar, de retirar tocos do solo durante o preparo do mesmo para semeá-lo.

${ }^{6}$ Refere-se ao ato de desfazer torrões de terra. 


\begin{tabular}{|c|c|c|}
\hline \multirow[t]{2}{*}{$\begin{array}{l}\text { Manejo de } \\
\text { máquinas } \\
\text { agrícolas }\end{array}$} & Aratórias & $\begin{array}{l}\text { Arados } \\
\text { Destocadores - tira tocos } \\
\text { Destorroadores - desfaz torrões } \\
\text { Grade } \\
\text { Plantadeiras mecânicas } \\
\text { Semeadeiras mecânicas } \\
\text { Carpideiras } \\
\text { Ceifadeiras } \\
\text { Sulcadores }\end{array}$ \\
\hline & Beneficiamento & $\begin{array}{l}\text { Descascadores, batedeiras } \\
\text { Irrigador de forragem } \\
\text { Moinho para cereais } \\
\text { Debulhadoras } \\
\text { Prensa, forno e ralo para o fabrico de farinha de } \\
\text { mandioca } \\
\text { fabrico de açúcar - engenho - cilindro, tachas, } \\
\text { alambiques } \\
\text { Desfibrador } \\
\text { Beneficiamento da mamona - prensa para óleo, torrador } \\
\text { refinador } \\
\text { Pilão }\end{array}$ \\
\hline \multicolumn{2}{|l|}{ Irrigação } & $\begin{array}{l}\text { Diques de inundação, drenos, nivelamento de terrenos } \\
\text { Açudes } \\
\text { Aproveitamento de águas subterrâneas: moinhos de } \\
\text { vento e poços tubulares }\end{array}$ \\
\hline \multicolumn{2}{|l|}{ Adubação } & $\begin{array}{l}\text { Orgânica: estercos e adubação verde } \\
\text { Inorgânica: cal, escoria Thomas, sulfato de potassa, } \\
\text { salitre do Chile, nitragina, cinzas }\end{array}$ \\
\hline \multicolumn{2}{|c|}{ Administração de fazendas } & $\begin{array}{l}\text { Escrituração agrícola: orçamento do custo de produção } \\
\text { por unidade de medida: preço das máquinas, custo de } \\
\text { instalação, custo da mão-de-obra, de cada um dos } \\
\text { serviços da lavoura, dedução de lucro. } \\
\text { Produção de relatórios }\end{array}$ \\
\hline \multicolumn{2}{|c|}{ Criação de animais } & $\begin{array}{l}\text { Animais de serviço - tração para máquinas agrícolas e } \\
\text { de beneficiamento - bois, muares e cavalares } \\
\text { Melhoramento de raças } \\
\text { Cuidados na manutenção de reprodutores: forragens, } \\
\text { imunização } \\
\text { Inseminação natural assistida }\end{array}$ \\
\hline \multicolumn{2}{|c|}{$\begin{array}{l}\text { Rudimentos de eletricidade } \\
\text { Rudimentos de mecânica }\end{array}$} & $\begin{array}{l}\text { Instalação de máquinas agrícolas } \\
\text { Pequenos concertos de máquinas agrícolas }\end{array}$ \\
\hline
\end{tabular}

Fontes: editoriais e artigos do jornal Minas Gerais, relatórios da diretoria de Agricultura.

Nos campos de demonstração instituídos em 1895 os aprendizes receberiam uma gratificação - que poderia chegar a doze mil réis no primeiro ano e quinze mil réis no segundo ano, mensais ${ }^{7}$ - além de alimentação, casa, roupa lavada e objetos de escritório

\footnotetext{
${ }^{7}$ Foi possível saber se era uma quantia irrisória comparando-a com a jornada ou diária de outros trabalhadores. Na primeira década do século 20 pagava-se, nas fazendas-modelos, aos operários agrícolas, que executavam serviços simples, como guias de bois, conhecidos como candeeiros, serviço em geral executados por crianças, diárias em torno de mil a mil e quinhentos réis de acordo com os relatórios da diretoria de Agricultura.
} 
(dec. 960/1896, art. 33). Esta gratificação poderia ser acrescida de um prêmio pecuniário, a depender do comportamento e dos serviços prestados durante a permanência no campo de demonstração. O decreto n. 960/1896 estipulava, ainda, uma espécie de certificação, um atestado dado ao final do segundo ano e

assinado pelo diretor e rubricado pelo Secretário de Estado da Agricultura, em que virão mencionados a permanência no estabelecimento, o seu comportamento e aptidões especiais, facilitando-Ihes assim a entrada nas explorações agrícolas, nos campos práticos ou em instituições análogas. (Art. 38)

As fazendas-modelo davam certificação apenas aos aprendizes a mestres de cultura e não aos operários agrícolas. Os aprendizes de formação mais rápida deveriam ser empregados dos fazendeiros, dispensando qualquer formalidade que garantisse ou promovesse-lhes o assalariamento. Além da certificação dada aos mestres de cultura, havia recompensas a eles, que poderia ser um emprego público na Diretoria de Agricultura. De fato, os primeiros mestres de cultura formados pela fazenda-modelo da Gameleira se tornaram técnicos a serviço da burocracia do Estado (Versieux, 2010). O decreto n. 2.027/1907 previa um exame oral, prestado junto à diretoria de Agricultura,

que versará sobre os diferentes trabalhos de campo com os respectivos instrumentos, e numa exposição sucinta e verbal, por meio de perguntas e respostas, das regras que se devem observar na cultura das espécies exploradas na fazenda, como o modo de plantação, as épocas próprias para as diferentes espécies; o modo de estrumação, irrigação, capina, colheitas etc.; e bem assim, em relação à administração, o modo de escrituração observado na fazenda e mais detalhes que tenham feito parte da sua aprendizagem. (Art. 22)

Essa certificação foi, portanto, mais rigorosa, introduzindo uma formalidade ou uma característica singular da escolarização do trabalho agrícola nas fazendas-modelo. Esta medida visou a garantir a aferição da capacidade dos técnicos de que o governo precisava para levar adiante a sua própria política. Há que se enfatizar também a instituição de um prêmio, no mesmo decreto n. 2.027/1907, aos cinco aprendizes mais destacados de cada turma, o que seria averiguado pelo exame acima referido. A cada um desses aprendizes o governo poderia "dar gratuitamente, a título de animação, um dos melhores lotes em qualquer das colônias do Estado, sempre que seu comportamento, durante todo o tempo de aprendizagem, nenhuma nota desfavorável tenha merecido" (art. 64). Não encontramos, porém, nenhuma evidência de que esses prêmios de fato tenham sido atribuídos aos aprendizes. Assim, nas fazendas-modelo, em relação aos campos de demonstração de fins do século 19, substituiu-se o atestado pelo exame oral, mas apenas aplicado aos aprendizes a mestres de cultura. Substituíram-se, também, os prêmios pecuniários pela doação de terrenos nas colônias agrícolas de povoamento.

Prosseguindo na comparação, observamos maior racionalização na condução prática da política de ensino agrícola por João Pinheiro. Este instituiu, como encarregados das direções das fazendas-modelo, dos campos de demonstração e das colônias de povoamento, pessoas de formação mais simples, os mestres de cultura, instruídos na própria fazenda-modelo da Gameleira. Os campos de demonstração, em fins do século 19, foram dirigidos por técnicos estrangeiros (Versieux, 2010). Há que se considerar a 
diminuição do número de funcionários técnicos das fazendas-modelo, se comparado com os vários profissionais que o decreto 960/1896 previa para os campos de demonstração. As fazendas-modelo contaram com um encarregado de sua administração, que era também o mestre de cultura responsável pelo ensino de agricultura, um ou dois auxiliares deste encarregado e vários trabalhadores agrícolas, que se empregavam por jornada nos momentos em que o número de aprendizes era insuficiente para dar continuidade aos serviços da lavoura. Dessa forma, João Pinheiro tentou criar estruturas que estariam mais de acordo com a visão contemporânea de restrição orçamentária da máquina burocrática do governo.

Aqui é preciso explicitar a diferença entre aprendizes a operários agrícolas e trabalhadores jornaleiros. Os aprendizes já eram trabalhadores agrícolas, enviados pelos fazendeiros para aprenderem o manejo das máquinas agrícolas. Não percebiam qualquer rendimento, mas tinham direito à moradia, alimentação e lavagem de roupas. Quanto aos jornaleiros, que também eram por vezes denominados operários agrícolas, recebiam um salário, pago na forma de jornal ou diária. Executavam os mesmos serviços que os aprendizes a operários agrícolas e não tinham direito a outras benesses. Pelo que se apurou, as fazendas-modelo não puderam prescindir desses trabalhadores devido ao pequeno número de aprendizes.

Outra diferença que sobressai da análise dos dois decretos - o n. 960/1896 e o n. 2.027/1907 - diz respeito à produção agrícola e pastoril. No decreto n. 960/1896 havia preocupação com a produção dos campos de demonstração, mas isso era secundário e dizia respeito, principalmente, à escrituração do estabelecimento e à venda ou consumo dos produtos produzidos internamente. $O$ cuidado com os aprendizes era mais acentuado, expresso na necessidade de registrá-los em livros, bem como os trabalhos executados por eles e a emissão do atestado em que constassem suas habilidades especiais e comportamento. Houve ainda a possibilidade de que pessoas estranhas ao estabelecimento assistissem aos trabalhos de cultura e criação (art. 53). Já com João Pinheiro a vinculação entre ensino e produção era mais estreita, recriando uma nova forma de aprendizagem dos métodos agrícolas.

No decreto n. 2.027/1907 não havia uma preocupação explícita com o registro das aprendizagens e dos trabalhos efetuados pelos aprendizes. Por outro lado, a produção ganhou relevo: estava-se interessado em mostrar que os métodos mais racionais eram economicamente viáveis; a escrituração não era somente um instrumento fiscalizador do Estado, fazia parte da própria aprendizagem, não apenas dos aprendizes, mas também dos fazendeiros que deveriam visitar as fazendas-modelo. Os fazendeiros passaram, assim, a serem alvos do ensino agrícola. Com João Pinheiro as fazendas tornaram-se a própria instituição estatal de ensino agrícola, às quais se juntaram, um pouco mais tarde, os institutos primário-agrícolas ${ }^{8}$. A fazenda tornou-se o centro da aprendizagem prática, formando mestres de cultura, ensinando o manejo de máquinas agrícolas aos aprendizes trabalhadores e convencendo os fazendeiros e lavradores a adotarem os processos modernos de cultura.

\footnotetext{
${ }^{8}$ Em 9 de fevereiro de 1909, pelo decreto n. 2.416 foi criado o Instituto João Pinheiro, na fazenda-modelo da Gameleira. Nesse mesmo ano, o Decreto n. 2.826, de 14 de maio, criou o Instituto Dom Bosco, que foi instalado somente em 30 de maio de 1910, em Itajubá. E, em $1^{\circ}$ de agosto de 1911, o decreto n. 3.261 instituiu o Instituto Bueno Brandão, situado no município de Mar de Espanha. 
Ao relegar e até mesmo descartar o ensino teórico essas instituições estariam voltadas para a produção: era primordial para o sucesso da política de ensino agrícola de João Pinheiro que as fazendas-modelo produzissem. E não apenas produzissem, mas que o fizessem em maior quantidade, melhor qualidade e com custos menores em relação aos métodos extensivos, ditos rotineiros. O caráter prático do ensino estava diretamente relacionado ao método de ensino empregado - o ensino intuitivo. Este ensino foi objeto de outro estudo, cujos resultados foram publicados por Versieux (2010).

A proposta de se criar fazendas-modelo, que João Pinheiro colocou em execução em 1906, previu a instalação de três tipos desses estabelecimentos, diferenciados pelo tipo de motor que, preferencialmente, empregariam: se motor animal, hidráulico ou elétrico. Diferenciaram-se, também, pelo tamanho da propriedade e, principalmente, pela complexidade das atividades que nelas se realizariam: se pequena produção, com máquinas agrícolas de tração animal; se produção maior; se aptas a beneficiar produtos agrícolas $^{9}$. O decreto n. 2.027, de 8 de junho de 1907, modificou os tipos de fazendasmodelo e enquadrou esses estabelecimentos conforme descrito no quadro 3.

Quadro 3 -

Tipos de fazendas-modelo, Minas Gerais, 1907.

\begin{tabular}{|c|l|l|l|l|}
\hline Tipos & \multicolumn{1}{|c|}{$\begin{array}{c}\text { Tamanho do } \\
\text { terreno }\end{array}$} & \multicolumn{1}{|c|}{$\begin{array}{c}\text { Máquinas } \\
\text { agrícolas }\end{array}$} & Tração & Tipos de cultura \\
\hline A & 10 alqueires & Aratórias & Animal & Um \\
\hline B & 25 alqueires & $\begin{array}{l}\text { Aratórias e de } \\
\text { beneficiamento } \\
\text { simples }\end{array}$ & Animal & Dois ou três \\
\hline C & 40 alqueires & $\begin{array}{l}\text { Aratórias e de } \\
\text { beneficiamento }\end{array}$ & Hidráulica & Policultura \\
\hline D & 80 alqueires & $\begin{array}{l}\text { Aratórias e de } \\
\text { beneficiamento }\end{array}$ & $\begin{array}{l}\text { Hidráulica ou } \\
\text { elétrica }\end{array}$ & $\begin{array}{l}\text { Policultura, } \\
\text { laticínios e } \\
\text { produtos } \\
\text { florestais }\end{array}$ \\
\hline
\end{tabular}

Fonte: decreto n. 2.027, 8 de junho de 1907.

$\mathrm{Na}$ prática, a divisão entre esses tipos não foi tão clara como previsto no regulamento. Ao que tudo indica nem mesmo chegou-se a implantar uma fazenda-modelo nos moldes do tipo D. As fazendas-modelo caracterizaram-se, no geral, por depender da tração animal, possuíam diversas culturas, dedicavam-se à criação de reprodutores de raça e variou bastante o tamanho das propriedades.

O referido regulamento deixou claro, também, que as seis fazendas-modelo previstas pela lei n. 438/1906 seriam apenas aquelas em que as despesas de instalação ocorressem por conta exclusiva do Estado, excluindo desse número as instaladas por iniciativa dos particulares e das câmaras municipais. Essas últimas, segundo o artigo 55, seriam "administradas e custeadas pelo Estado diretamente, pertencendo-lhe a propriedade e o respectivo rendimento". Dessa forma, o decreto n. 2.027/1907 ampliou, em relação à lei n. 438/1906, a possibilidade de instalarem-se fazendas-modelo no Estado. Esta ampliação é que permitiu a criação de algumas fazendas-modelo sem,

${ }^{9}$ De acordo com o editorial Agricultura, publicado no jornal Minas Gerais, de 25/11/1906, cuja autoria é atribuída a João Pinheiro. 
contudo, que o seu número fosse mais significativo do que o previsto na lei n. 438/1906.

A proposta de criação das fazendas-modelo, tanto no que observamos no regulamento promulgado com o decreto n. 2.207/1907, quanto nas discussões da tramitação do projeto n. 167/1906, que deu origem à lei n. 438/1906, levou-nos a inferir que essas fazendas tinham por missão agir como polos de desenvolvimento para as diferentes regiões do Estado (Versieux, 2010; Gonçalves, Versieux, 2009). Mesmo não aparecendo a expressão polos de desenvolvimento nas discussões da lei, nem no seu texto legislativo, o fato dos parlamentares usarem a expressão desenvolvimento no sentido de progresso econômico das regiões menos adiantadas do Estado, como o próprio norte de Minas, nos autorizou a utilizar a expressão acima. Contudo, é preciso assinalar que, a despeito das discussões encetadas na Câmara dos Deputados mineira, as fazendas-modelo foram instaladas em cidades em geral antigas, servidas por estradas de ferro e, portanto, com algum grau de desenvolvimento. Além disso, nem todas as zonas tiveram suas fazendas-modelo, como pode ser observado no quadro 4 . Ao que tudo indica, a escolha dos locais de instalação das fazendas-modelo obedeceu a critérios antes políticos do que econômicos. Dessa forma, a sua atuação como polos de desenvolvimento regional ficou comprometida desde muito cedo.

Quadro 4 -

Localização, data e instrumento de criação das fazendas-modelo, Minas Gerais, 1906-1914.

\begin{tabular}{|l|c|c|c|l|}
\hline $\begin{array}{c}\text { Fazendas- } \\
\text { modelo }\end{array}$ & Município & Região & $\begin{array}{c}\text { Data de } \\
\text { criação }\end{array}$ & Instrumento de criação \\
\hline Gameleira & Belo Horizonte & Centro & $26 / 11 / 06$ & $\begin{array}{l}\text { Compra de terrenos pelo governo } \\
\text { estadual. }\end{array}$ \\
\hline Fábrica & Serro & Centro/Norte & $25 / 9 / 07$ & $\begin{array}{l}\text { Decreto 2.099/1907. Compra de } \\
\text { terrenos pelo governo estadual. }\end{array}$ \\
\hline $\begin{array}{l}\text { Retiro do } \\
\text { Recreio }\end{array}$ & Santa Bárbara & Centro & $27 / 11 / 07$ & $\begin{array}{l}\text { Decreto 2.129/1907. Doação de } \\
\text { terrenos pela Câmara Municipal } \\
\text { de Santa Bárbara. }\end{array}$ \\
\hline Diniz & Itapecerica & Oeste & $4 / 12 / 07$ & $\begin{array}{l}\text { Decreto 2.131/1907. Doação de } \\
\text { terrenos por particulares. }\end{array}$ \\
\hline Aiuruoca & Aiuruoca & Sul & $11 / 3 / 1908$ & $\begin{array}{l}\text { Decreto 2.201/1908. Doação de } \\
\text { terrenos pela Câmara Municipal } \\
\text { de Aiuruoca. }\end{array}$ \\
\hline Bairro Alto & Campanha & Sul & $27 / 11 / 08$ & $\begin{array}{l}\text { Decreto 2.309/1908. Transfe- } \\
\text { rência de propriedade da União } \\
\text { para o Estado. }\end{array}$ \\
\hline
\end{tabular}

Fonte: Relatórios da diretoria de Agricultura, 1908 e 1909, jornal Minas Gerais (1907-1909).

Entre 1906 e 1909 foram várias as tentativas de se criarem fazendas-modelo, tanto por parte do governo, quanto pelas municipalidades e até mesmo por particulares. Maria Auxiliadora Faria indica que

pela lei n. 438, de 24 de setembro de 1906, o governo foi autorizado a criar 6 fazendas modelo, das quais só 5 foram efetivamente instaladas: Fazenda Modelo da Gameleira, em Belo Horizonte; da Fábrica, no Serro; do Retiro do Recreio, em Sta. Bárbara; Diniz, em Itapecerica e Bairro Alto, 
em Campanha. O regulamento de 1911 ampliou a possibilidade de criação de novas fazendas, desde que conveniadas com os governos municipais. Apesar dos incentivos do Estado às eventuais iniciativas dos municípios, nenhum deles manifestou interesse e o número das fazendas modelo não foi alterado. (Faria, 1992, p. 273)

Apuramos que por iniciativa do governo estadual foram criadas somente três das fazendas-modelo citadas por Maria Auxiliadora Faria: a da Gameleira, a da Fábrica e a do Bairro Alto (ver quadro 4). As duas primeiras tiveram seus terrenos escolhidos por João Pinheiro e a última foi criada a partir de uma doação de terras feita pelo governo federal. A localização, por zona e por município, destas e das outras fazendas-modelos que existiram durante o período estudado, estão descritas no quadro 4 e representadas na figura 1.

Como já visto, a lei n. 438/1906, promulgada cinco anos antes do regulamento de 1911, citado por Faria, já previa arranjos entre câmaras municipais e particulares com o governo estadual. Contudo, o decreto que regulamentou esta lei, n. 2.027/1907, não determinou como seriam os acordos entre particulares e governo. Em todo caso, os municípios poderiam ceder terrenos para que o governo implantasse as fazendas-modelo. Os entendimentos entre governo estadual e proprietários particulares eram incentivados pela imprensa oficial e a Diretoria de Agricultura terminou por enquadrar as iniciativas particulares de se fundar fazendas-modelo no mesmo artigo 55, do decreto n. 2.027/1907.

Um editorial do jornal Minas Gerais, cuja autoria é atribuída a João Pinheiro (Versieux, 2010; Barbosa, 1980), explicava que o Congresso Mineiro havia votado verba de 500 contos de réis para auxiliar as municipalidades que quisessem fundar fazendasmodelo. Assim,

por este meio e com tão pequeno sacrifício, o povo verá o que é um arado, um rolo, uma grade e como estas máquinas trabalham e que imensas vantagens as da sua aplicação, e, estabelecido este pequeno núcleo em cada município, não será difícil que a ação se irradie pelos distritos. (Minas Gerais, 1907, p. 1)

João Pinheiro acreditava que, dessa forma, o ensino agrícola se espalharia pelo Estado, utilizando-se poucos recursos. Consideramos que esta sua concepção, de que o progresso do Estado viria necessariamente com a contribuição e, mais do que isso, com a participação ativa das municipalidades, vinculou-se à sua experiência na Câmara Municipal de Caeté, no período em que esteve afastado da política do Estado. João Pinheiro assumiu a presidência da Câmara Municipal e as funções de agente executivo de Caeté em $1^{\circ}$ de janeiro de 1899 (Barbosa, 1980), implantando, a partir de então, uma série de medidas que apareceriam, tanto nas teses do Congresso Agrícola de 1903, quanto no seu manifesto-programa como candidato à presidência do Estado de Minas Gerais. Instituiu, por exemplo, prêmios de produção agrícola e pastoril à iniciativa privada e organizou a I Feira Municipal de Caeté, ocorrida em setembro de 1902 (Barbosa, 1980). No manifesto-programa de sua candidatura à presidência de Minas declarou, em 1906, que esperava ser

eficazmente auxiliado pelos governos municipais. Eles gozam na República e principalmente em Minas, de ampla liberdade de ação; achamse em contato direto com o povo, e, portanto, devendo realizar, em menor 
esfera, o mesmo pensamento que inspira o Governo do Estado, cuidando mais de administração e menos de política, ou seguindo a verdadeira política. [...] Que a renda municipal seja aplicada em obras públicas, [...]; que se estabeleçam prêmios para o incentivo e aumento da produção; que se reduza ao mínimo o funcionalismo municipal; [...] Semelhante política fará que as localidades prosperem, sendo resultante a prosperidade do Estado. (Pinheiro, In: Barbosa, 1980, p.195)

João Pinheiro, antes da sua posse como presidente do Estado, empreendeu uma excursão, em junho de 1906, "por diversos municípios da Zona da Mata, sem aviso prévio, sem se fazer acompanhar de comitiva e sem qualquer protocolo" (Barbosa, 1980, p. 22). E, após tornar-se chefe do executivo mineiro, participou de todos os congressos das municipalidades, ocorridos nas zonas mineiras do Sul, Norte e da Mata ${ }^{10}$. Num editorial do jornal Minas Gerais conclamou as municipalidades a se unirem ao governo nessa empreitada, solicitando a elas que concorressem "com o mínimo de terras e subvenção [...] e se terá generalizado por todo Estado o ensino e o emprego das máquinas agrícolas. Não vale a pena o sacrifício por parte das municipalidades?" (Minas Gerais, 1907, p. 1).

De alguma forma as municipalidades atenderam a convocação de João Pinheiro. Conforme informado no jornal Minas Gerais, houve pelo menos quinze iniciativas municipais para a fundação de fazendas-modelo que não se efetivaram, sendo doze tentativas por parte das câmaras municipais e três iniciativas particulares (ver quadro 5). Apesar de a verba ter sido votada e as terras terem sido oferecidas pelas municipalidades e por particulares, as iniciativas não foram transformadas em realidade, em boa parte dos casos. De fato, a maioria das tentativas de se implantar fazendas-modelo, por essa via, não resultou em efetivação deste tipo de estabelecimento e fracassaram.

Além dessas, houve mais três iniciativas municipais que obtiveram sucesso. A fazenda-modelo Diniz, em Itapecerica, instituída por decreto, foi criada a partir da doação de terrenos por particulares da cidade. Já a fazenda Retiro do Recreio, em Santa Bárbara, e o campo de demonstração de Aiuruoca, situado nos arredores da cidade de mesmo nome, foram instituídos, também por decreto, mas tendo como ponto de partida os terrenos doados pelas respectivas câmaras municipais.

\section{Quadro 5 -}

Iniciativas municipais de se criar fazendas-modelo, Minas Gerais, 1907-1909.

\begin{tabular}{|l|l|c|}
\hline \multicolumn{1}{|c|}{ Município } & \multicolumn{1}{|c|}{ Iniciativa } & \multicolumn{1}{c|}{$\begin{array}{c}\text { Data da edição do jornal } \\
\text { Minas Gerais }\end{array}$} \\
\hline $\begin{array}{l}\text { Santa Luzia do Rio das } \\
\text { Velhas }\end{array}$ & $\begin{array}{l}\text { Particular. Grupo Agrícola de } \\
\text { Traíras }\end{array}$ & $19 / 10 / 1906$ \\
\hline Ouro Fino & Câmara Municipal & $22 / 2 / 1907$ \\
\hline Santa Bárbara & Câmara Municipal & $10 / 7 / 1907$ \\
\hline Cataguases & Câmara Municipal & Junhol1907 \\
\hline
\end{tabular}

${ }^{10}$ O Congresso das Municipalidades do Sul ocorreu em Itajubá, entre os dias 26 e 28 de abril de 1907; o das Municipalidades do Norte reuniu-se na cidade de Diamantina, entre 20 e 22 de setembro do mesmo ano; já o Congresso da Mata foi instalado na cidade de Leopoldina, entre os dias 12 e 14 de outubro de 1907 (Barbosa, 1980).

${ }^{11}$ Esta data se refere ao início do processo de doação das terras pelas municipalidades, que culminaram na criação de duas fazendas-modelo. 


\begin{tabular}{|l|l|c|}
\hline Cambuí & Câmara Municipal & $10 / 7 / 1907$ \\
\hline Itapecerica & $\begin{array}{l}\text { Particular - Lamounier } \\
\text { Godofredo }\end{array}$ & $3 / 8 / 1907$ \\
\hline Aiuruoca $^{12}$ & Câmara Municipal & Novembro/1907 \\
\hline Itapecerica $^{13}$ & $\begin{array}{l}\text { Particular - Major Ignácio } \\
\text { Ferreira Diniz } \\
\text { e Beralda Rita Diniz }\end{array}$ & $8 / 11 / 1907$ \\
\hline Cristina & Câmara Municipal & $2 / 11 / 1907$ \\
\hline Uberaba & Câmara Municipal & $2 / 11 / 1907$ \\
\hline- & $\begin{array}{l}\text { Particular. Coronel Francisco } \\
\text { de Oliveira }\end{array}$ & $2 / 12 / 1907$ \\
\hline Dores do Indaiá & Câmara Municipal & $30-31 / 12 / 1907$ \\
\hline Araguari & Câmara Municipal & $26 / 3$ e 21/12/1908 \\
\hline Ponte Nova & Câmara Municipal & $11-12 / 5 / 1908$ \\
\hline Santa Rita da Extrema & Câmara Municipal & $9 / 7 / 1908$ \\
\hline Alvinópolis & Câmara Municipal & $12 / 8 / 1908$ \\
\hline Juiz de Fora & Câmara Municipal & $21-22 / 12 / 1908$ \\
\hline Peçanha & Câmara Municipal & $4 / 6 / 1909$ \\
\hline
\end{tabular}

Fonte: Jornal Minas Gerais, set. 1906, mar. 1915.

O jornal Minas Gerais noticiou, em 19 de setembro de 1906, menos de 15 dias após a posse de João Pinheiro, que havia chegado às mãos do novo presidente do Estado "as propostas de sete municipalidades mineiras, no sentido de se estabelecerem nos respectivos municípios as fazendas modelo" (p. 6, col. 3). Isso eleva a vinte e cinco as tentativas municipais de se instalar fazendas-modelos, incluindo aquelas que efetivamente foram implantadas. Esse dado indicou que a criação de fazendas-modelo no Estado despertou senão o entusiasmo, ao menos o interesse das autoridades municipais.

Foi possível averiguar que algumas tentativas não deram resultados concretos devido aos terrenos oferecidos não satisfazerem as condições exigidas para a fundação de uma fazenda-modelo. Porém, nem sempre se indicou quais condições não foram satisfeitas. De maneira geral, a Diretoria de Agricultura, ao aprovar a instalação de fazendas-modelo em terrenos cedidos por particulares ou câmaras municipais, avaliou que estes possuíam uma parte de terrenos planos ou pouco inclinados, o que permitiria a utilização de máquinas agrícolas aratórias, e dispunham de água suficiente para irrigação de lavouras. Após 1909, mesmo antes, portanto, do regulamento aprovado em 1911, não mais foram criadas fazendas-modelo, apesar das inúmeras tentativas que relatei.

Daquelas que chegaram a ser criadas, em lei ou de fato, identificamos sete. Dessas apenas a fazenda-modelo D. Antônia Augusta, instituída pelo decreto n. 2.113, de 14 de outubro de 1907, no município de Leopoldina, não deve ter sido de fato instalada. Das poucas referências encontradas sobre esta fazenda, consegui apurar que sua área, pertencente à Câmara Municipal de Leopoldina, foi adquirida por seis mil contos de réis. Em seguida, foi anexada à colônia de povoamento Barão de Aiuruoca, situada no município de Mar de Espanha, pela necessidade de se aumentar os terrenos da mesma.

A fazenda-modelo de Aiuruoca, citada no quadro 4 e criada num distrito do município do mesmo nome, foi transformada, pelo decreto n. 2.262, de 12 de agosto de 1908, em campo de demonstração, tendo uma existência efêmera enquanto fazenda-modelo.

\footnotetext{
${ }^{12}$ Esta data se refere ao início do processo de doação das terras pelas municipalidades, que culminaram na criação de duas fazendas-modelo.

${ }^{13}$ Esta data refere-se ao dia em que os terrenos foram efetivamente doados.
Hist. Educ. [Online]
Porto Alegre
n. 46
Maio/ago., 2015
p. 201-222

v. 19
} 
Entretanto, o campo de demonstração existiu até 1919 e escapou de ser arrendado ou vendido por não ser mais uma fazenda-modelo, apesar de em tudo similar. É necessário demarcar os limites entre fazendas-modelo e os campos de demonstração, justificando a inclusão do campo de demonstração de Aiuruoca nesta pesquisa, que se concentra nas fazendas-modelo.

A legislação dos primeiros anos republicanos, as proposições dos deputados e senadores quando das discussões no Congresso Legislativo Mineiro, no que toca ao ensino agrícola, e as opiniões veiculadas pela Revista Industrial de Minas Gerais, consentem em uma indistinção entre os termos fazenda-modelo e campo de demonstração. Maria Auxiliadora Faria (1992) distingue esses dois tipos de estabelecimentos, mas descrevendo-os de maneira muito próxima, sendo ambos definidos como instituições de ensino agrícola prático. Os campos de demonstração eram, de acordo com Maria Auxiliadora Faria, responsabilidade das municipalidades, pois, "segundo o regulamento de 1911, eles deviam concorrer com terrenos apropriados e significativas quantias financeiras, cabendo ao governo estadual a supervisão técnica" (Faria, 1992, p. 282). Porém, já fizemos perceber que os campos de demonstração existiram muito antes desse regulamento e que foram instalados por iniciativa do governo.

Ao compararmos esses tipos de estabelecimentos que existiram em fins do século 19 e as fazendas-modelo do início do século 20 , é possível elencar diversas diferenças entre eles. O tipo de organização, estrutura de ensino, o currículo ora mais, ora menos prático. Contudo, o que diferenciou as fazendas-modelo dos campos de demonstração foram as singularidades de cada uma dessas experiências históricas que, mesmo próximas no tempo, foram resultados de políticas distintas e mesmo que complementares.

Identificamos os campos de demonstração como uma política de ensino agrícola centrada na aprendizagem por meio da demonstração das técnicas e processos modernos de agricultura. Nas fazendas-modelo a aprendizagem centrava-se na demonstração da viabilidade produtiva das mesmas técnicas. Além disso, os campos de demonstração, que existiram a partir da assunção de João Pinheiro à presidência do Estado foram, com exceção do de Aiuruoca, instalados como anexos a colônias de povoamento. Podemos citar como exemplos aqueles que existiram nas colônias de Nova Baden, Itambacuri e Francisco Sales. Dessa forma, por compreendermos que no campo de demonstração de Aiuruoca a aprendizagem tinha por base a produção, incluímos este estabelecimento neste estudo.

As fazendas-modelo que de fato existiram o foram até 1914/1915, quando foram suprimidas por uma lei orçamentária. A partir de 1915 algumas foram vendidas, outras arrendadas, sendo que apenas a fazenda da Gameleira continuou existindo enquanto tal, vinculada que estava ao Instituto João Pinheiro. O campo de demonstração de Aiuruoca funcionou ainda por alguns anos, como já salientei, e a fazenda Diniz prestou serviços por mais de uma década ao Estado, após sucessivos contratos de arrendamento. O que importa assinalar é que a política de ensino agrícola baseada nas fazendas-modelo encerrou-se em 1915.

Estas instituições tiveram uma existência de fato e não apenas nos textos emanados do legislativo ou do executivo. Foram administradas pela Diretoria de Agricultura e não tinham uma existência isolada umas das outras. Ao contrário, tudo indica que a Diretoria de Agricultura imprimiu um caráter de rede entre as fazendas-modelos, e destas com 
outros estabelecimentos, como os campos de demonstração, de experiências, os institutos, aprendizados e colônias agrícolas. Assim, é possível compreendê-las nessa rede, por onde circulavam funcionários da diretoria, fazendeiros, aprendizes, informações, conhecimentos e produtos agrícolas e pastoris.

Mesmo integradas a uma rede de propaganda e ensino agrícola primário e elementar, as fazendas-modelo não obedeceram, do mesmo modo, às orientações político-administrativas emanadas da Diretoria de Agricultura. De todas elas, somente a fazenda-modelo da Gameleira formou mestres de cultura. As demais receberam aprendizes trabalhadores para instrução técnica aligeirada. Receberam também diversos visitantes, umas mais, outras menos. Do que foi possível apurar, foi pequena a frequência de aprendizes e talvez de fazendeiros que as visitaram, em comparação com a fazendamodelo da Gameleira. Quanto aos visitantes, não nos foi possível mensurá-los ou qualificá-los, a não ser aqueles que frequentaram a fazenda-modelo da Gameleira, assim mesmo de forma precária.

Na tabela 1 relacionamos o número de aprendizes em cada fazenda-modelo e no campo de Aiuruoca, entre 1907 e 1914. Como já salientamos o número de aprendizes no período, nas fazendas-modelo, foi cerca de oito vezes menor se comparado com a aprendizagem nas fazendas subvencionadas. Importa assinalarmos que as informações desse quadro diferem um pouco daquelas elencadas por Maria Auxiliadora Faria (1992). Assim, para os anos de 1910 a 1914, Faria apurou o número de 103 aprendizes para a Gameleira, treze para a Fábrica e nenhum para as outras fazendas-modelo. De acordo com a tabela 1, para o mesmo período considerado por Faria, encontramos também 103 aprendizes na Gameleira, doze na Fábrica, cinco na Retiro do Recreio, treze na fazendamodelo Diniz e seis na do Bairro Alto, além de ter incluído o campo de demonstração de Aiuruoca. Atribuímos esta diferença às fontes utilizadas, pois Faria (1992) citou apenas os relatórios da Secretaria de Agricultura, enquanto nós consultamos também os relatórios da diretoria de Agricultura, que se revelaram em geral mais completos.

Em todas as fazendas-modelo fez-se alto investimento, de forma a dotá-las da infraestrutura necessária para os fins a que se destinaram, o que nem sempre aconteceu. A tabela 2 mostra o dispêndio, em moeda da época, com a instalação, manutenção e obras de adaptação da infraestrutura, e o valor das receitas de cada fazenda-modelo. 
Tabela 1 -

Número de aprendizes das fazendas-modelo do Estado de Minas Gerais, 19071914.

\begin{tabular}{c|c|c|c|c|c|c|c}
\hline \multirow{2}{*}{ Anos } & \multicolumn{5}{|c|}{ Fazendas-modelo } & \multicolumn{2}{c}{$\begin{array}{c}\text { Total } \\
\text { anual }\end{array}$} \\
\cline { 2 - 8 } & Gameleira & Fábrica & $\begin{array}{c}\text { Retiro do } \\
\text { Recreio }\end{array}$ & Aiuruoca & Diniz & Bairro Alto & \\
\hline 1907 & 51 & - & 7 & - & 4 & - & 62 \\
\hline 1908 & 50 & - & - & - & - & - & 50 \\
\hline 1909 & 30 & - & - & - & 18 & - & 48 \\
\hline 1910 & 23 & 3 & - & 7 & 13 & - & 46 \\
\hline 1911 & 14 & 3 & - & - & 1 & - & 16 \\
\hline 1912 & 29 & 4 & 1 & 40 & - & 4 & 38 \\
\hline 1913 & 19 & 2 & - & 5 & - & 2 & 28 \\
\hline 1914 & 17 & - & 4 & - & - & - & 21 \\
\hline & 233 & 12 & 12 & 12 & 36 & 6 & 309 \\
\hline
\end{tabular}

Fontes: Relatórios publicados pela Diretoria de Agricultura e pela Secretaria da Agricultura 1908-1915.

Tabela 2 -

Receitas e despesas das fazendas-modelo, Minas Gerais, 1906-1914.

\begin{tabular}{|c|c|c|c|c|c|c|c|c|c|c|c|c|c|c|}
\hline & & & & & & Faze & 10 & & & & & & & \\
\hline & Gam & eleira & Fáb & brica & Retiro do & Recreio & $\mathrm{Di}$ & niz & Aiur & ruoca & Bairr & o Alto & tal & anual \\
\hline Anos & Receitas & Despesas $^{14}$ & Receitas & Despesas & Receitas & Despesas & Receitas & Despesas & Receitas & Despesas & Receitas & Despesas & Receitas & Despesas \\
\hline 906 & - & $00 \$ 000$ & - & 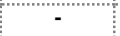 & & . & & & - & & & & & 8:000s \\
\hline 907 & $20: 221 \$ 200$ & $156: 249 \$ 732$ & "'-" & $6: 744 \$ 130$ & & $3: 754 \$ 770$ & - & $2: 520 \$ 075$ & - & 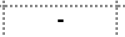 & & & $20: 221 \$ 200$ & $169: 169 \$$ \\
\hline 908 & $20: 183 \$ 369$ & $37: 691 \$ 569$ & - & $38 \$ 500$ & $400 \$ 000$ & $13: 226 \$ 060$ & $375 \$ 100$ & $4: 842 \$ 875$ & - & $14: 153 \$ 280$ & & - & $0: 958 \$ 469$ & $75: 552 \$$ \\
\hline 909 & $24: 123 \$ 827$ & $46: 882 \$ 297$ & $2: 760 \$ 999$ & $6: 206 \$ 270$ & $7: 671 \$ 560$ & $25: 256 \$ 176$ & $9: 886 \$ 460$ & $9: 756 \$ 710$ & $1: 408 \$ 273$ & $4: 333 \$ 003$ & $4: 862 \$ 000$ & $16: 635 \$ 977$ & $50: 713 \$ 119$ & $109: 070 \$$ \\
\hline 10 & $13: 739 \$ 187$ & $20: 617 \$ 300$ & $2: 841 \$ 840$ & 6 & 937 & $31: 739 \$ 086$ & $4: 2$ & 18 & 5980 & 5 & 1 & $23:$ & $27: 3$ & $106: 479 \$$ \\
\hline 111 & $10: 494 \$ 560$ & $12: 853 \$ 870$ & $2: 755 \$ 500$ & $8: 242 \$ 782$ & $4: 155 \$ 330$ & 13:31 & $5: 922 \$ 620$ & $8: 975 \$ 525$ & $1: 027 \$ 945$ & $5: 532 \$ 225$ & $1: 792 \$ 000$ & $22: 842 \$ 586$ & $26: 147 \$ 955$ & 71:763\$ \\
\hline 12 & $10: 169 \$ 867$ & $15: 879 \$ 067$ & $1: 581 \$ 400$ & $11: 296 \$ 548$ & $3: 278 \$ 946$ & & $3: 477 \$ 239=$ & $14: 385 \$ 855$ & $1: 241 \$ 430$ & $2: 067 \$ 140$ & $3: 015 \$ 768$ & $15: 358 \$ 176$ & $22: 764 \$ 650$ & $68: 457$ \\
\hline 13 & $9: 445 \$ 300$ & $27: 467 \$ 300$ & $1: 264 \$ 175$ & $12: 304 \$ 060$ & $1: 213 \$ 260$ & $8: 454 \$ 100$ & $6: 562 \$ 253$ & $10: 615 \$ 149$ & $735 \$ 000$ & $2: 722 \$ 316$ & $3: 555 \$ 400$ & $12: 657 \$ 955$ & $22: 775 \$ 388$ & $74: 220$ \\
\hline 14 & $6: 925 \$ 997$ & $16: 560 \$ 137$ & $1: 441 \$ 075$ & $6: 986 \$ 020$ & $1: 622 \$ 860$ & $30 \$ 298$ & $3: 316 \$ 887$ & $10: 405 \$ 135$ & $1: 156 \$ 500$ & $1: 876 \$ 000$ & 600 & $9: 362 \$ 650$ & $15: 952 \$ 009$ & $: 42$ \\
\hline & & $342: 201 \$ 272$ & $12: 644 \$ 98$ & $64: 391 \$ 540$ & $19: 279 \$ 256$ & $110: 448 \$ 505$ & $33: 819 \$ 958$ & $80: 206 \$ 674$ & $9: 149 \$ 218$ & $35: 816 \$ 004$ & $16: 65$ & $100: 169 \$ 504$ & $206: 859 \$ 332$ & $733: 134 \$ 4$ \\
\hline
\end{tabular}

Fontes: Relatórios da diretoria de Agricultura e da Secretaria de Agricultura publicados entre 1908 e 1915. Para o ano de 1906, jornal Minas Gerais.

Pelos dados disponíveis, vemos que nem sempre foi possível separar as despesas de custeio e manutenção das despesas de obras de infraestrutura, o que melhor demonstraria o custo de cada fazenda e a relação com a produção agrícola. Por isso, agrupamos todas as despesas em uma coluna apenas. Esta tabela não é exata, fornecendo informações apenas aproximadas, apesar dos dados utilizados terem sido coletados de fontes oficiais. Algumas das despesas feitas com as fazendas-modelo e

\footnotetext{
${ }^{14}$ Nas despesas, incluí, além do custeio e manutenção do estabelecimento, as despesas com obras de meIhoria e ampliação da estrutura, além do custo de aquisição dos terrenos, quando foi o caso.
} 
campo de demonstração de Aiuruoca foram diluídas em outras rubricas. Isso aconteceu, por exemplo, em relação aos pagamentos dos encarregados de suas direções e à rubrica Máquinas Agrícolas.

Algumas fazendas-modelo tiveram sua atuação ampliada a partir do final de 1908. Passaram a contar com postos zootécnicos, destinados à aclimatação e reprodução de animais de raça. Esses animais destinavam-se à venda a particulares, como forma de melhorar os rebanhos do Estado, atingindo, assim, melhores preços nos mercados. Também algumas dificuldades se prolongaram, como o abastecimento de água. Algumas delas conseguimos captar por meio dos documentos produzidos pela própria diretoria. Os problemas administrativos foram comuns. Em algumas fazendas-modelo teve-se uma alta rotatividade de administradores, em outras mais estabilidade. De forma geral, essas trocas de administradores foram efetuadas depois da expedição de vários ofícios, solicitando cuidados com a prestação de contas, o envio de documentos comprobatórios dos gastos efetuados, proibindo gastos não autorizados. Contudo, a despeito dessas semelhanças, muitas eram as diferenças, que ressaltamos na tabela 3 .

Tabela 3 -

Área total e ocupada por plantações nas fazendas-modelo, Minas Gerais, 19071914

\begin{tabular}{l|c|c|c|c|c|c}
\hline \multicolumn{1}{c|}{ Fazendas-modelo } & Gameleira & Fábrica & $\begin{array}{c}\text { Retiro do } \\
\text { Recreio }\end{array}$ & Diniz & Aiuruoca & Bairro Alto \\
\hline $\begin{array}{l}\text { Tamanho } \\
\text { alqueires }\end{array}$ & 44 & 25 & 100 & 15 & 15 & 300 \\
\hline $\begin{array}{l}\text { Área ocupada com plantações } \\
\text { em alqueires }\end{array}$ & 10,33 & 6,6 & 6,6 & 5,57 & 2,52 & 6,2 \\
\hline $\begin{array}{l}\text { Área ocupada com plantações } \\
\text { em relação à área total do } \\
\text { terreno }\end{array}$ & $23,50 \%$ & $26,40 \%$ & $6,60 \%$ & $37,13 \%$ & $16,80 \%$ & $2,06 \%$ \\
\hline
\end{tabular}

Fontes: Relatórios da diretoria de Agricultura e da secretaria de Agricultura publicados entre os anos de 1908 e 1915, referentes aos exercícios de 1907 a 1914

Assim, é possível salientar que houve um maior desenvolvimento referente à fazenda-modelo da Gameleira, em comparação com os outros estabelecimentos. A fazenda constituiu-se em uma referência para este estudo, pois era ela a mais bem instalada - na Capital -, documentada, fiscalizada e concentrava maiores somas de investimento público. Além disso, a Gameleira teve uma maior relevância em termos de formação de aprendizes agrícolas. Esta fazenda ministrou o ensino agrícola prático a um número muito superior de aprendizes em relação às outras quatro fazendas-modelo e ao campo de Aiuruoca. Em que pese ter sido maior a quantidade de aprendizes formados na Gameleira, qualitativamente houve uma diferenciação na formação que lá se ministrou, pois foi nesta fazenda que se formaram os mestres de cultura, elementos fundamentais para a institucionalização das fazendas-modelo e da política de João Pinheiro.

${ }^{15}$ Os valores apresentados sofreram alterações de ano para ano e correspondem à maior área ocupada entre os anos de 1907 e 1914. 


\section{Referências}

ARQUIVO PRIVADO DE JOÃO PINHEIRO DA SILVA. Série II - Correspondências. Arquivo Público Mineiro, Belo Horizonte, Minas Gerais.

BARBOSA, Francisco de Assis. As idéias políticas de João Pinheiro: cronologia, introdução, notas bibliográficas e textos selecionados. Brasília: Senado Federal/MEC; Rio de Janeiro: Fundação Rui Barbosa, 1980.

BRASIL. DIÁRIO OFICIAL. Decretos n. 8.255, 8.357 e 8358 - 9 nov. 1910.

BRASIL. DIÁRIO OFICIAL. Decretos n. 8.365 e 8367 - 10 nov. 1910.

DIRETORIA DE AGRICULTURA, COMÉRCIO, TERRAS E COLONIZAÇÃO. Relatórios anuais referentes aos anos de 1907 a 1927. Belo Horizonte: Imprensa Oficial do Estado de Minas Gerais. 1908-1927. Arquivo Público Mineiro; Biblioteca Estadual Luiz de Bessa (Coleção Mineiriana).

DULCl, Otávio. João Pinheiro e as origens do desenvolvimento mineiro. In: GOMES, Ângela de Castro (org.). Minas e os fundamentos do Brasil moderno. Belo Horizonte: UFMG, 2005, p. 109-136.

FARIA, Maria Auxiliadora. A política da gleba: as classes conservadoras mineiras; discurso e prática na primeira república. São Paulo: USP, 1992. 394f. Tese (doutorado em História Social). Faculdade de Filosofia, Letras e Ciências Humanas, Universidade de São Paulo.

FUNDO AFONSO PENA (ON). Microfilmes n. AN 523-2004; AN 536-2004. Arquivo Nacional, Rio de Janeiro.

GONÇALVES, Irlen Antônio. Cultura escolar: práticas e produção dos grupos escolares em Minas Gerais (1891/1918). Belo Horizonte: Autêntica, 2006.

GONÇALVES, Irlen Antônio; VERSIEUX, Daniela Pereira. A criação das fazendas-modelo em Minas Gerais: a política pública para a educação profissional republicana nas primeiras décadas do século 20. CONGRESSO IBEROAMERICANO DE HISTÓRIA DA EDUCAÇÃO LATINO-AMERICANA, 9, 2009. Anais ... Rio de Janeiro: Quartet, 2009, p. 415.

MINAS GERAIS (jornal). Belo Horizonte: Imprensa Oficial do Estado de Minas Gerais. 01/set/1906-31/mar/1915. Imprensa Oficial de Minas Gerais.

MINAS GERAIS. Coleção de leis e decretos. Belo Horizonte: Imprensa Oficial, 1898-1930. MINAS GERAIS. Coleção de leis e decretos. Ouro Preto: Imprensa Oficial, 1892-1897.

MONTEIRO, Norma Góes (coord.). Dicionário biográfico de Minas Gerais - período republicano - 1889/1991. Belo Horizonte: Assembleia Legislativa do Estado de Minas Gerais, 1994. 2v.

PENNA, Affonso Augusto Moreira. Mensagem apresentada ao Congresso Nacional. Rio de Janeiro: Imprensa Nacional, 1907.

REVISTA INDUSTRIAL DE MINAS GERAIS. Publicação mensal auxiliada pelo governo do Estado. Ouro Preto: Emop, 15 out. 1893-15 dez. 1897, anos I-V.

SECRETARIA DA AGRICULTURA, INDÚSTRIA, TERRAS, VIAÇÃO E OBRAS PÚBLICAS. Relatórios anuais referentes aos anos de 1910-1917; 1919; 1922; 1922-1925; 1927-1930. Belo Horizonte: Imprensa Oficial do Estado de Minas Gerais. Biblioteca da Faculdade de Ciências Econômicas da Universidade Federal de Minas Gerais (Coleção Mineiriana); Biblioteca Estadual Luiz de Bessa. 
VERSIEUX, Daniela Pereira. Modernização e escolarização do trabalho agrícola: as fazendas-modelo em Minas Gerais (1906-1915). Belo Horizonte: Cefet, 2010. 232f. Dissertação (mestrado em Educação Tecnológica). Centro Federal de Educação Tecnológica de Minas Gerais.

IRLEN ANTÔNIO GONÇALVES é professor no Centro Federal de Educação Tecnológica de Minas Gerais.

Endereço: Avenida Bernardo Vasconcelos 2500/607 - 31160-440 - Belo Horizonte MG - Brasil.

E-mail: irlen@terra.com.br.

DANIELA PEREIRA VERSIEUX é professora no Instituto Federal de Educação, Ciência e Tecnologia de Goiás, campus Formosa.

Endereço: Rua 64 esquina com rua 11, s/n - 73813-816 - Formosa - GO - Brasil.

E-mail: danielaversieux@gmail.com.

Recebido em 26 de janeiro de 2013.

Aceito em 12 de setembro de 2014. 